\title{
Marginal Health Care Expenditure Burden Among U.S. Civilian Noninstitutionalized Individuals with Multiple Sclerosis: 2010-2015
}

\author{
Jagadeswara Rao Earla, PharmD, MBA; J. Douglas Thornton, PhD, PharmD, BCPS; \\ George J. Hutton, MD; and Rajender R. Aparasu, PhD, FAPhA
}

\begin{abstract}
BACKGROUND: Multiple sclerosis (MS) is a chronic neuroinflammatory disorder with significant health care burden. However, little is known about health care expenditures since the introduction of oral agents for MS after 2010.

OBJECTIVE: To analyze health care expenditures in individuals with MS using Medical Expenditure Panel Survey (MEPS) data from 2010-2015.

METHODS: This retrospective cross-sectional study included adults ( $\geq 18$ years) with MS (Clinical Classification Code 080) and those without MS based on the 2010-2015 full year consolidated MEPS Household Component and Medical Provider Component data files. Descriptive weighted analyses were performed to compare health care expenditures between individuals with MS and without MS. The 2-part model involving probit and generalized linear models was used to estimate the marginal increase in total health care expenditures for MS patients.
\end{abstract}

RESULTS: There were 0.61 million patients $(95 \% \mathrm{Cl}=0.50-0.72)$ diagnosed with MS annually, accounting for a prevalence of $0.25 \%$. The 2-part model revealed that the marginal total health care expenditures in patients diagnosed with MS were $\$ 20,103.49(95 \% \mathrm{Cl}=\$ 14,516.24-\$ 25,690.73)$ more compared with those without MS. Further, the mean adjusted prescription medication expenditures for the MS group were $\$ 13,092.16(95 \%$ $\mathrm{Cl}=\$ 9,452.20-\$ 16,732.12)$ higher than the non-MS group and accounted for $65.12 \%$ of total health care expenditures in MS.

CONCLUSIONS: MS is an expensive neuroinflammatory disease with a majority of the burden attributable to prescription medications. High prescription expenditure burden can be a barrier to optimal patient care in MS.

J Manag Care Spec Pharm. 2020;26(6):741-49

Copyright $\odot 2020$, Academy of Managed Care Pharmacy. All rights reserved.

\section{What is already known about this subject}

Despite an increasing number of disease-modifying agents (DMAs) the cost of DMAs has been rising beyond inflation, relative to the average inflation rate of drug costs and other biological drugs. As per National Multiple Sclerosis Society estimates, the total annual health care expenditures associated with MS in the United States are $\$ 28$ billion.

\section{What this study adds}

These study findings show that the marginal health care expenditures among individuals with MS were $\$ 20,104$ more compared with those without MS

A major portion (65\%) of the health expenditures among MS patients was attributable to expensive DMAs, making treatment inaccessible.

This study reveals that concerted efforts are needed to minimize the coverage hurdles and copay burden for DMAs to improve quality of care in MS.

$\mathrm{M}$ ultiple sclerosis (MS) is a complex, chronic, autoimmune neuroinflammatory disorder of the central nervous system characterized by neuronal demyelination and axonal loss, resulting in distorted communications within the brain and spinal cord and also between the brain and body. ${ }^{1-4}$ The clinical presentation of MS can be overwhelming, causing a broad range of symptoms such as pain, fatigue or weakness, sensory difficulties, and disturbances in cognition, mobility, vision, urination, and sexual activity. ${ }^{4}$ It is a leading cause of nontraumatic disability in younger adults., Further, MS significantly impacts functional capacity, cognition, and quality of life, and requires lifelong treatment. ${ }^{7,8}$ The recent prevalence estimate of MS in the United States is nearly 1 million, or 300 patients per 100,000 individuals. ${ }^{9,10}$ The incidence rate of MS is higher for people who are female, young adults, white, and it increases with distance from the equator. ${ }^{7,8,11-13}$ Comorbidity burden and mortality rate are also relatively high among individuals with MS. ${ }^{14,15}$

Treatment of MS includes a 3-pronged approach: (1) use of disease-modifying agents (DMAs) to reduce relapses and to prevent disease progression, (2) use of steroids to treat acute relapses, and (3) symptomatic treatment to alleviate the broad array of MS symptoms such as fatigue, impaired ambulation, and spasticity., Relapsing-remitting MS is the most common type of MS (80\%-90\%) and requires treatment with DMAs. ${ }^{5}$ Management of MS has evolved significantly in the last 2 decades with the advent of several new MS drugs. ${ }^{2}$ Among the 15 DMAs currently available, most were approved after 2010. ${ }^{7}$ Even after the introduction of several new DMAs into 
the market, DMA costs increased 5 to 7 times compared with other drugs' inflation, including biologics. ${ }^{16-19}$

As per National Multiple Sclerosis Society (NMSS) estimates, the total annual health care expenditures associated with MS in the United States are $\$ 28$ billion. ${ }^{11,20}$ In Adelman et al.'s review (2013), annual health care expenditures for MS patients (including prescription medications) ranged from $\$ 22,055$ to $\$ 37,549$ per patient (in 2011 dollars). Direct costs (i.e., costs directly associated with health care consultation, follow-up, medications, and other medical interventions) accounted for $77 \%$ of the total expenditures, ranging from $\$ 16,625$ to $\$ 34,511$ per patient (in 2011 dollars). ${ }^{21,22}$

Several researchers studied health care expenditures among the MS population using data before 2010 (i.e., before the introduction of newer MS agents such as fingolimod, teriflunomide, and dimethyl fumarate). ${ }^{8,22-24}$ Kobelt et al.'s survey (2006) of randomly selected individuals with MS from the North American Research Committee on Multiple Sclerosis Patient Registry reported an annual direct cost of $\$ 29,634$ per patient. ${ }^{25}$ In another study by Campbell et al. (2014) using Medical Expenditure Panel Survey (MEPS) data (1998-2009), direct costs associated with MS in the United States were $\$ 24,327$ per patient more than those without MS. ${ }^{26}$ However, nationally representative data regarding health care expenditures in the MS population since 2010, after the introduction of several newer MS drugs into the market, is limited. ${ }^{7}$ Health care burden analysis can help to understand the changing expenditure landscape in MS. Therefore, this retrospective cross-sectional study aimed to update the health care expenditures associated with MS in the United States based on the recent nationally representative MEPS data (2010-2015).

\section{Methods}

\section{Data Source}

This retrospective, cross-sectional, observational study used the MEPS data from 2010 to 2015 to examine health care expenditures among individuals with MS. The MEPS is a nationally representative survey of the U.S. civilian noninstitutionalized population sponsored by the Agency for Healthcare Research and Quality (AHRQ) and cosponsored by the Centers for Disease Control and Prevention's National Center for Health Statistics. ${ }^{27}$ It includes 4 components: Household Component (HC), Medical Provider Component (MPC), Insurance Component (IC), and Nursing Home Component. MEPS-HC is the core part of the survey and forms the basis of MPC and IC. ${ }^{28-30}$ Altogether, MEPS provides extensive information on type, frequency, and charges of health care services, allowing researchers to examine the current dynamics of American health care use and how different patient characteristics influence their medical care and expenditures. ${ }^{27,28,31}$ MEPS-HC consists of an overlapping panel design in which a given sample selected during each year is followed for more than 2 calendar years facilitating both cross-sectional and longitudinal data analyses. The MEPS involves a complex, stratified, multistage, and disproportionate sampling. ${ }^{28,32}$ The sample population is obtained from the respondents to the National Health Interview Survey. Further information regarding MEPS survey design, data, and variables can be accessed on the AHRQ website. ${ }^{28}$

This study used HC and MPC parts of MEPS data. HC is the primary person-level file with information collected from household respondents regarding demographics, medical conditions, services, charges and payments, income, employment, and insurance coverage. The MEPS is event-level information collected from providers regarding the medical care provided to MEPS household respondents. The MPC supplements HC by providing additional and accurate information on medical conditions, charges, and payments reported by the households. The HC files provide comprehensive expenditure information from various health care components, including prescriptions and provider charges. ${ }^{27,29}$ The prescription expenditures include DMAs (oral, subcutaneous, and intramuscular injections), and charges from providers can include infusions.

Pooled data from 6 years (2010-2015) of MEPS-HC and MPC files were used to analyze health care expenditures in individuals with MS. The sampling weight variable in MEPS-HC was adjusted by dividing it with the duration of data (in years) considered (i.e., 6 , to get the annual estimates). This study was exempt from review by the institutional review board at the University of Houston as MEPS is publicly available and deidentified data.

\section{Study Sample and Operational Definition}

The study sample consisted of individuals diagnosed with MS between 2010 and 2015. Diagnosis data in MEPS-MPC were coded according to the International Classification of Diseases, Ninth Revision, Clinical Modification (ICD-9-CM). All the ICD codes, including V-codes, were aggregated into 263 mutually exclusive, clinically meaningful categories using Clinical Classification Software as clinical classification codes (CCCs) in MEPS-MC files. ${ }^{32-34}$ Individuals with MS were identified from the MEPS-HC medical condition files with CCC 080, which corresponds to ICD-9-CM code 340. All the remaining individuals without MS diagnosis were considered as the comparative non-MS group. The study included all patients who were considered in-scope of the civilian noninstitutionalized population based on positive MEPS sampling weights.

\section{Health Care Expenditures}

Total all-cause health care expenditures are an aggregate of expenditures related to hospital inpatient, outpatient, emergency room, prescription medications, dental, vision, home health care, and other medical services (glasses, ambulance, and equipment). Expenditure estimates in MEPS-HC are 
payments (amount paid for health care services) made by patients and payers, not based on costs to the providers. ${ }^{27,35}$ Medical expenditure data from all 6 years (2010-2015) were inflated to a common 2017-dollar value (nominal dollars) using the medical care component of the Consumer Price Index obtained from the Bureau of Labor Statistics. ${ }^{36,37}$

\section{Covariates}

All the independent variables or covariates were defined based on the self-reported responses of households available in the MEPS data. Age category, sex, region, race/ethnicity, education, marital status, income class, and insurance are the other independent variables used/derived based on the survey responses of MEPS-HC data. In addition, Elixhauser Comorbidity Index score, a frequently used and valid summary score representative of comorbidity burden, was computed comprehending the weighted information of 30 different comorbidities and considered as another covariate. Adjusting for Elixhauser index score helps in estimating the increase in health expenditures based on patients' comorbidity burden and provides a better marginal cost estimate. ${ }^{38}$ Finally, the calendar year in the pooled data was coded as 2010, 2011, 2012, 2013, 2014, and 2015.

\section{Statistical Analyses}

Descriptive statistics were calculated to compare the characteristics and health care expenditures between MS and non-MS groups. Two-part model (TPM), which allows for mixed discretecontinuous dependent variables, was used to analyze the marginal total health care expenditures among the MS group over the non-MS group, adjusted for all the covariates. ${ }^{39}$ In the first part, a probit model was specified to estimate the probability of having zero versus positive (greater than zero dollars) health care expenditures. Conditional on having any positive expenditure, a generalized linear model was specified in the second part of the model to estimate the marginal health care expenditure between MS and non-MS groups. The best-fitting generalized linear model was selected after verifying the appropriateness of the family distribution and the link function. Modified Park Test determined that current study data resemble Poisson family distribution. The Pregibon link test confirmed log link function as the suitable link function. In addition, multicollinearity was also ruled out by calculating the variance inflation factor. TPM is widely used to analyze the health care expenditures to improve the precision of estimates and to address common issues with excessive zeros and positive skewness.

This TPM allows calculating the marginal effects and standard errors by using estimates from both parts of the model. ${ }^{32,39-41}$ As a part of the sensitivity analyses, marginal expenditures were computed by changing the second part of the TPM to gamma family distribution instead of Poisson family distribution. Gamma family distribution was considered for sensitivity analyses, since it is the most commonly used family distribution to model health care expenditures.

SAS 9.4 (SAS Institute, Cary, NC) was used for descriptive weighted analyses, and STATA 14.2 (StataCorp, College Station, TX) was used to perform TPM in order to compute marginal expenditures associated with MS diagnosis. MEPS sample selection follows a multistage probability design. Hence, all the analyses were adjusted for the complex survey design using the cluster, strata, and weight variables to obtain nationally representative estimates and standard errors. Adjusting for the sampling weight variables helps to produce national weighted estimates from the sample of individuals considered for the study and accounts for nonresponse and other sampling considerations.

\section{Results}

\section{Patient Characteristics}

This study cohort included 303 individuals with MS diagnosis representing an annual national weighted population of 609,357 (95\% confidence interval $[\mathrm{CI}]=496,576$ $722,138)$, accounting for an estimated annual prevalence of $0.25 \%$ in the United States. The comparative non-MS group consisted of 145,657 individuals (weighted frequency $=237,562,815$ ). The mean age of the adult MS group was 53.19 years versus 46.89 years for the non-MS group. The study sample characteristics are provided in Table 1 . Characteristics such as age, sex, race/ethnicity, education, and marital status significantly differed for the MS and non-MS groups. The mean Elixhauser index score (range $=-19,89$ ) of the MS group was 0.32 (vs. 0.40 for the non-MS group). A higher proportion of patients in the MS group (44.49\%) had 2 or more comorbidities compared with the non-MS group (28.12\%). Most common Elixhauser comorbidities seen in MS patients were arthritis (40.34\%), depression (36.75\%), hypertension uncomplicated (28.58\%), chronic lung disease (13.71\%), and hypothyroidism (6.87\%).

\section{All-Cause Health Care Expenditures}

The total all-cause annual direct health care expenditures of adult MS cohort were estimated to be $\$ 18.65$ billion (95\% $\mathrm{CI}=13.68-23.63)$. Comparison of unadjusted mean health care expenditures between MS and non-MS groups by type of health care service are shown in Table 2 and Figure 1 . The mean unadjusted annual total health care expenditures for the MS group $(\$ 30,616 ; 95 \% C I=\$ 24,941.29-\$ 36,290.37)$ were significantly higher compared with non-MS group $(\$ 5,826.28$; $95 \% \mathrm{CI}=\$ 5,673.41-\$ 5,979.15)$. Also, the mean unadjusted annual expenditures for prescription medicines for the MS group $(\$ 16,795 ; 95 \% \mathrm{CI}=\$ 12,914.53-\$ 20,674.90)$ were higher than for the non-MS group $(\$ 1,346.69 ; 95 \% C I=\$ 1,289.17$ $\$ 1,404.22$ ). Prescription medication expenditures among the MS group accounted for more than half (55\%) of total all-cause health care expenditures (vs. non-MS 23\%). 


\begin{tabular}{|c|c|c|c|c|c|}
\hline \multirow[b]{2}{*}{ Variable } & \multicolumn{2}{|c|}{ MS Group } & \multicolumn{2}{|c|}{ Non-MS Group } & \multirow[b]{2}{*}{$P$ Value } \\
\hline & Weighted Frequency & $\%$ & Weighted Frequency & $\%$ & \\
\hline \multicolumn{6}{|l|}{ Age, years } \\
\hline $18-44$ & 149,635 & 24.56 & $111,407,443$ & 46.90 & $<0.001$ \\
\hline $45-64$ & 349,174 & 57.30 & $82,068,031$ & 34.55 & \\
\hline$\geq 65$ & 110,548 & 18.14 & $44,087,342$ & 18.56 & \\
\hline \multicolumn{6}{|l|}{ Sex } \\
\hline Male & 177,474 & 29.12 & $114,743,261$ & 48.30 & $<0.001$ \\
\hline Female & 431,884 & 70.88 & $122,819,554$ & 51.70 & \\
\hline \multicolumn{6}{|l|}{ Race/ethnicity } \\
\hline White & 352,843 & 57.90 & $112,600,323$ & 47.40 & 0.027 \\
\hline Black/African American & 53,295 & 8.75 & $22,514,995$ & 9.48 & \\
\hline Hispanic & 42,849 & 7.03 & $35,813,516$ & 15.08 & \\
\hline Other & 160,371 & 26.32 & $66,633,982$ & 28.05 & \\
\hline \multicolumn{6}{|l|}{ Region } \\
\hline Northeast & 148,210 & 24.32 & $43,156,423$ & 18.17 & 0.167 \\
\hline Midwest & 146,795 & 24.09 & $50,768,265$ & 21.37 & \\
\hline South & 179,575 & 29.47 & $88,207,136$ & 37.13 & \\
\hline West & 134,778 & 22.12 & $55,430,991$ & 23.33 & \\
\hline \multicolumn{6}{|l|}{ Education } \\
\hline Less than high school & 40,796 & 6.69 & $33,981,916$ & 14.37 & 0.044 \\
\hline High school diploma/GED & 174,268 & 28.60 & $73,647,286$ & 31.15 & \\
\hline Associates/bachelors degree & 305,067 & 50.06 & $103,761,494$ & 43.89 & \\
\hline Masters or higher & 89,226 & 14.64 & $25,026,463$ & 10.59 & \\
\hline \multicolumn{6}{|l|}{ Marital status } \\
\hline Single/never married & 78,390 & 12.86 & $65,908,844$ & 27.74 & $<0.001$ \\
\hline Married & 384,519 & 63.10 & $125,095,390$ & 52.66 & \\
\hline Widowed/divorced/separated & 146,448 & 24.03 & $46,556,147$ & 19.60 & \\
\hline \multicolumn{6}{|l|}{ Income category/poverty class } \\
\hline Poor/near poor & 103,232 & 16.94 & $39,977,877$ & 16.83 & 0.721 \\
\hline Low income & 64,314 & 10.55 & $32,073,300$ & 13.50 & \\
\hline Middle income & 185,594 & 30.46 & $70,256,970$ & 29.57 & \\
\hline High income & 256,218 & 42.05 & $95,254,668$ & 40.10 & \\
\hline \multicolumn{6}{|l|}{ Insurance type } \\
\hline Private & 425,843 & 69.88 & $161,101,249$ & 67.81 & 0.631 \\
\hline Nonprivate $^{\mathrm{a}}$ & 183,514 & 30.12 & $76,461,567$ & 32.19 & \\
\hline \multicolumn{6}{|l|}{ Comorbidities } \\
\hline 1 or none & 338,274 & 55.51 & $170,765,920$ & 71.88 & $<0.001$ \\
\hline \multirow[t]{2}{*}{2 or more } & 271,084 & 44.49 & $66,796,895$ & 28.12 & \\
\hline & Mean (SD) & $95 \% \mathrm{CI}$ & Mean (SD) & $95 \% \mathrm{CI}$ & \\
\hline Age & $53.19 \quad(1.16)$ & $50.91-55.47$ & $46.89 \quad(0.18)$ & $46.53-47.26$ & $<0.050$ \\
\hline Elixhauser Comorbidity Index score & $0.32 \quad(0.29)$ & $-0.25-0.89$ & $0.40 \quad(0.02)$ & $0.37-0.43$ & $<0.050$ \\
\hline
\end{tabular}

\section{Marginal and Incremental Health Care Expenditures}

The marginal total health care expenditures in the MS group, after adjusting for all the covariates, including Elixhauser index score and calendar year, were $\$ 20,103.49$ (95\% CI $=14,516.24$ 25,690.73) more compared with individuals with non-MS. As shown in Table 3, age category, sex, race/ethnicity, region, education, marital status, income/poverty class, insurance, and Elixhauser index score showed significant association with total health care expenditures.

The mean adjusted total health care expenditures for the MS group were $\$ 20,103.49$ (95\% CI $=\$ 14,516.24-\$ 25,690.73$ ) compared with patients in the non-MS group (Table 4). Further, the mean adjusted prescription medicine expenditures for the MS 


\begin{tabular}{|c|c|c|c|c|}
\hline \multirow[b]{2}{*}{ Type of Health Care Service } & \multicolumn{2}{|c|}{ MS Group, \$ } & \multicolumn{2}{|c|}{ Non-MS Group, \$ } \\
\hline & Mean & $95 \% \mathrm{CI}$ & Mean & $95 \%$ CI \\
\hline Totala & $30,616.00$ & $24,941.29-36,290.37$ & $5,826.28$ & $5,673.41-5,979.15$ \\
\hline Hospital inpatient & $4,104.34$ & $1,938.93-6,269.74$ & $1,633.08$ & $1,551.62-1,714.54$ \\
\hline Ambulatorya & $6,428.13$ & $4,648.68-8,207.58$ & $2,184.58$ & $2,120.53-2,248.63$ \\
\hline Outpatient ${ }^{\mathrm{a}}$ & $5,453.66$ & $4,045.41-6,861.92$ & $1,947.53$ & $1,887.39-2,007.67$ \\
\hline Emergency room & 974.47 & $7.19-1,941.74$ & 237.05 & $227.31-246.79$ \\
\hline Prescription medications $^{a}$ & $16,795.00$ & $12,914.53-20,674.90$ & 1,346 & $1,289.17-1,404.22$ \\
\hline Dental & 504.39 & $312.85-695.92$ & 318.97 & $308.46-329.49$ \\
\hline Vision & 90.08 & $53.09-127.07$ & 58.55 & $56.09-61.01$ \\
\hline Home health and others ${ }^{a, b}$ & $2,694.16$ & $1,275.28-4,113.04$ & 284.40 & $249.59-319.21$ \\
\hline Total excluding prescription medications $s^{\mathrm{a}, \mathrm{c}}$ & $13,821.00$ & $10,028.80-17,613.39$ & $4,479.59$ & $4,351.19-4,607.99$ \\
\hline \multicolumn{5}{|c|}{$\begin{array}{l}\text { aP<0.05 (significantly different). } \\
{ }^{b} \text { Others include glasses, ambulance, and equipment. } \\
{ }^{c} \text { Calculated as total health care expenditures minus prescription medication expenditures. } \\
C I=\text { confidence interval; } M S=\text { multiple sclerosis. }\end{array}$} \\
\hline
\end{tabular}

group were $\$ 13,092.16(95 \% \mathrm{CI}=\$ 9,452.20-\$ 16,732.12$ ) higher than the non-MS group. The adjusted prescription medication expenditures in individuals with MS accounted for $65.12 \%$ of total health care expenditures.

\section{Sensitivity Analysis}

When expenditures were modeled with gamma family distribution, marginal total health care expenditures were $\$ 24,559.38$ (95\% CI $=\$ 18,447.81-\$ 30,670.95)$ for individuals with MS compared with non-MS— $\$ 4,455.89$ more than when modeled with Poisson distribution. Furthermore, marginal prescription medication expenditures in individuals with MS were $\$ 16,092.80$ (95\% CI $=\$ 11,851.23-\$ 20,334.37)-\$ 3,000.64$ more than when modeled with Poisson distribution. The percentage of marginal prescription expenditures out of marginal total health expenditures when modeled with gamma distribution (65.53\%) did not vary much with Poisson distribution $(65.12 \%)$.

\section{Discussion}

This study, using 2010-2015 MEPS data, found MS prevalence estimate of $0.25 \%$; the previous estimate was $0.21 \%$ based on 1998-2009 MEPS data. ${ }^{26}$ The NMSS recently estimated MS prevalence of $0.31 \%$, or 309.2 per 100,000 , based on multiple national claims datasets. ${ }^{9,10}$ Consistent with the existing literature, a high proportion of the MS population in this study were middle-aged (45-64 years), female, white, and had private insurance. . $3,26^{2}$

Based on MEPS data, the total annual direct health care expenditures of the current adult MS cohort were estimated to be $\$ 18.65$ billion. Whereas, previous annual direct cost estimate from the NMSS in MS patients was $\$ 16$ billion in 2009 dollars. ${ }^{11}$ Further, the annual total cost estimate in 2009 was
$\$ 28$ billion. $^{20}$ In this study, the unadjusted difference in total health care expenditures between MS and non-MS groups was $\$ 24,790$ per person. Previous studies reported direct medical costs ranging from $\$ 18,100$ to $\$ 19,741$ in 2017 dollars. ${ }^{8,11}$ The current study estimate is higher than the previous study estimates even after adjusting for inflation, indicating the increasing economic burden among MS individuals in recent years. ${ }^{24}$ More than half (54.86\%) of total health care expenditures were attributable to prescription expenditures. Prescott et al. (2007) reported that the prescription medication expenditures in the MS group accounted for $64.8 \%$ of the total annual expenditures. ${ }^{8}$ In this study, the unadjusted difference in expenditures for prescribed medications between MS and non-MS groups was $\$ 15,448$. In addition, hospital inpatient, ambulatory, outpatient, home health, and other expenditures were higher in the MS group over the non-MS group, reemphasizing the increased need for health care resources and associated expenditures for MS.

The adjusted marginal total health care expenditures in the MS group over the non-MS group were $\$ 20,104$ (95\% $\mathrm{CI}=\$ 14,516-\$ 25,691)$. However, a study by Campbell et al. (2014) using MEPS data showed much higher marginal health care expenditures for MS patients at \$24,327 (\$28,889 in 2017 dollars). This difference in marginal expenditures could be because of 2 main reasons. First, Campbell et al. used ordinary least squares regression to compute marginal expenditures, unlike the TPM. ${ }^{26}$ Recent literature suggests the use of TPM to analyze expenditure data to address right skewness and excessive zero expenditures, and to avoid retransformation bias while obtaining cost estimates. ${ }^{40-42}$ Further, Campbell et al. added an extra $\$ 17,085$ annually per patient toward DMA costs. Authors justified adding this literature-based estimate of DMA costs by mentioning the limitations of MEPS data in terms of coding 
FIGURE 1 Unadjusted Mean Health Care Expenditures of MS and Non-MS Patients by Health Care Service: Medical Expenditure Panel Survey 2010-2015

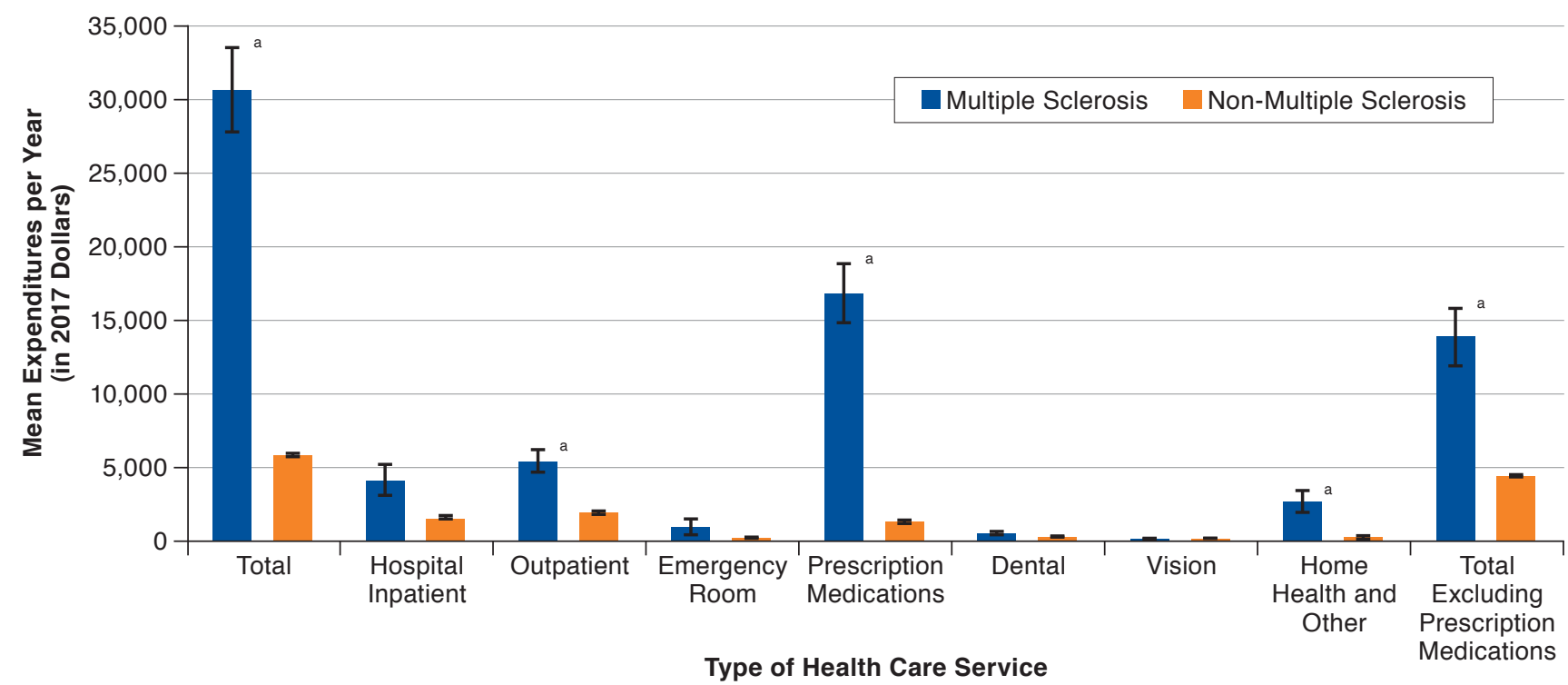

${ }^{a}<0.05$

injectable medications. ${ }^{26}$ The current study estimate of $\$ 20,104$ is underestimated compared with Kim et al.'s (2019) estimate of annual health care costs among individuals with MS, which ranged from $\$ 45,471$ to $\$ 62,500$, evaluating data from 2011 to $2015 .{ }^{43}$ This vast difference in cost estimates can be attributed to the differences in population and reimbursements; while the current study used expenditure data from a nationally representative sample involving all insurances, Kim et al. used IBM MarketScan commercial insurance claims data. ${ }^{43}$ However, the marginal estimates of the current study are consistent with the systematic review by Adelman et al. that assessed the cost burden of MS; the direct costs associated with MS diagnosis ranged from $\$ 16,625-\$ 34,511$ in 2011 dollars $(\$ 19,742$.84$\$ 40,983.16$ adjusted to 2017 dollars). ${ }^{22}$

In this study, a major proportion (65.12\%) of the total health care expenditures was because of prescription medications. The adjusted prescription expenditures in the MS group were $\$ 13,092.16$ higher compared with the reference population. Consistent with previous literature, prescription expenditures are the main driver behind total health care expenditures in the MS population..$^{8,16,23,43-45}$ Health Care Cost Institute report (2019) and Carroll et al. (2014) also reported that among individuals with MS, DMAs occupy $53 \%$ of the total costs. ${ }^{23,45}$ Whereas in this study, among those who were on at least 1 DMA prescription, DMAs occupied $75 \%$ of the total costs. ${ }^{8,16,23,44}$ The proportional difference in prescription expenditures could be attributed to the use of TPM with gamma distribution to analyze expenditures. However, the percentage distribution of expenditures among different health care services (inpatient hospital, outpatient, emergency room, prescription medications, dental, vision, and home health and others) was almost the same.

These national study findings are noteworthy, as they can inform the significant health care burden among the MS population in the United States. A major portion of health expenditures among MS patients was attributable to expensive DMA prescription medications. Even though the introduction of oral DMAs after 2010 facilitated ease of use and has increased treatment options for MS patients, the costs of DMAs have been increasing year to year beyond inflation for the last 2 decades. Evidence suggests that the annual inflation rate among DMAs is significantly higher than the inflation rate among biologics. The percentage change in median cost per quarter was significantly higher for DMAs compared with tissue necrosis factor (TNF) inhibitors (DMAs vs. TNF inhibitors $2001-2006: 3.3 \%$ vs. $1.3 \%$; 2006-2010: $4.6 \%$ vs. $1.4 \%$; $2010-2013: 3.7 \%$ vs. $3.1 \%) .{ }^{16-19}$ This has been attributed to a lack of generic competition and specifically to a free-market drug pricing system in the United States. Studies have consistently shown that highly priced DMAs are making the treatment inaccessible to a majority (70\%) of the MS population. ${ }^{18,19,44,46}$ Hence, managed care clinicians, providers, and payers were recommended to minimize the coverage hurdles and to provide sufficient access to DMAs for individuals with MS. ${ }^{16}$ 


\begin{tabular}{|c|c|c|}
\hline $\begin{aligned} \text { TABLE 3 } & \text { Marc } \\
& \text { in M } \\
& \text { Med } \\
& 2010\end{aligned}$ & $\begin{array}{l}\text { hal Health Ca } \\
\text { Adjusted for } \\
\text { al Expenditur } \\
2015\end{array}$ & $\begin{array}{l}\text { expenditures } \\
\text { er Covariates: } \\
\text { anel Survey }\end{array}$ \\
\hline Variable & $\begin{array}{c}\text { Marginal/ } \\
\text { Incremental } \\
\text { Expenditures, \$ }\end{array}$ & $95 \% \mathrm{CI}$ \\
\hline \multicolumn{3}{|l|}{$\overline{\text { MS }}$} \\
\hline Yes & $20,103.49$ & $14,516.24,25,690.73^{a}$ \\
\hline No & Reference & - \\
\hline \multicolumn{3}{|l|}{ Sex } \\
\hline Female & 639.55 & $349.14,929.96^{\mathrm{a}}$ \\
\hline Male & Reference & - \\
\hline \multicolumn{3}{|l|}{ Age, years } \\
\hline $45-64$ & $3,335.22$ & $2,973.57,3,696.87^{a}$ \\
\hline$\geq 65$ & $5,423.24$ & $4,991.99,5,854.49^{a}$ \\
\hline $18-44$ & Reference & - \\
\hline \multicolumn{3}{|l|}{ Race/ethnicity } \\
\hline Black/African American & -565.42 & $-1,048.48,-82.37 \mathrm{a}$ \\
\hline Hispanic & $-1,528.61$ & $-1,918.28,-1,138.95^{a}$ \\
\hline Other & -448.54 & $-860.13,-36.96^{a}$ \\
\hline White & Reference & - \\
\hline \multicolumn{3}{|l|}{ Region } \\
\hline Northeast & $1,311.25$ & $740.23,1,882.28^{a}$ \\
\hline Midwest & 753.47 & $376.13,1,130.80^{\mathrm{a}}$ \\
\hline West & 269.64 & $-152.35,691.63$ \\
\hline South & Reference & - \\
\hline \multicolumn{3}{|l|}{ Education } \\
\hline Less than high school & -465.87 & $-932.04,0.30$ \\
\hline High school diploma/GED & -338.33 & $-684.29,7.63$ \\
\hline Masters or higher & 507.12 & $3.88,1,010.36^{a}$ \\
\hline $\begin{array}{l}\text { Associates/bachelors } \\
\text { degree }\end{array}$ & Reference & - \\
\hline \multicolumn{3}{|l|}{ Marital status } \\
\hline Married & 361.42 & $-80.22,803.06$ \\
\hline $\begin{array}{l}\text { Widowed/divorced/ } \\
\text { separated }\end{array}$ & 812.75 & $329.48,1,296.01^{a}$ \\
\hline Single/never married & Reference & - \\
\hline \multicolumn{3}{|c|}{ Income category/poverty class } \\
\hline Poor/near poor income & $1,866.99$ & $1,387.28,2,346.71^{\mathrm{a}}$ \\
\hline Low income & 767.46 & $278.18,1,256.74^{a}$ \\
\hline Middle income & 149.43 & $-253.75,552.61$ \\
\hline High income & Reference & - \\
\hline \multicolumn{3}{|l|}{ Insurance } \\
\hline Private & 496.28 & $158.89,833.67^{\mathrm{a}}$ \\
\hline Nonprivate $^{b}$ & Reference & - \\
\hline $\begin{array}{l}\text { Elixhauser Comorbidity } \\
\text { Index score }\end{array}$ & 623.15 & $566.95,679.35^{a}$ \\
\hline \multicolumn{3}{|l|}{ Year } \\
\hline 2011 & 132.00 & $-303.94,567.94$ \\
\hline 2012 & -453.40 & $-979.80,72.99$ \\
\hline 2013 & -251.91 & $-734.53,230.72$ \\
\hline 2014 & -15.91 & $-459.64,427.82$ \\
\hline 2015 & 522.36 & $-21.78,1,066.50$ \\
\hline 2010 & Reference & - \\
\hline \multicolumn{3}{|c|}{ 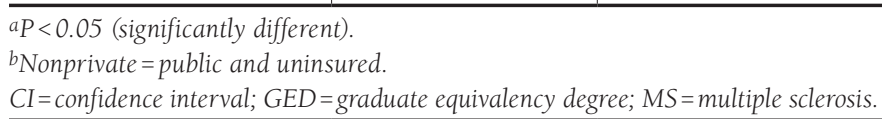 } \\
\hline
\end{tabular}

\begin{tabular}{|c|c|c|c|}
\hline TABLE 4 & \multicolumn{3}{|c|}{$\begin{array}{l}\text { Marginal Health Care Expenditures in MS } \\
\text { Patients by Health Care Service: Medical } \\
\text { Expenditure Panel Survey 2010-2015 }\end{array}$} \\
\hline $\begin{array}{l}\text { Type of Health } \\
\text { Care Service }\end{array}$ & $\begin{array}{c}\text { Marginal } \\
\text { Expenditures, \$ }\end{array}$ & $95 \% \mathrm{CI}$ & $\begin{array}{l}\text { Percentage } \\
\text { of the Total } \\
\text { Unadjusted } \\
\text { Health Care } \\
\text { Expenditures }\end{array}$ \\
\hline Total $^{\mathrm{a}}$ & $20,103.49$ & $14,516.24-25,690.73$ & 100.00 \\
\hline Hospital inpatient & $1,592.09$ & $247.01-3,431.20$ & 7.92 \\
\hline Outpatient ${ }^{\mathrm{a}}$ & $2,341.55$ & $1,072.64-3,610.46$ & 11.65 \\
\hline Emergency room & 647.21 & $244.79-1,539.20$ & 3.22 \\
\hline $\begin{array}{l}\text { Prescription } \\
\text { medications }^{\mathrm{a}}\end{array}$ & $13,092.16$ & $9,452.20-16,732.12$ & 65.12 \\
\hline Dental & 105.24 & $63.70-274.19$ & 0.52 \\
\hline Vision & 9.95 & $-18.40-38.30$ & 0.05 \\
\hline $\begin{array}{l}\text { Home health and } \\
\text { others } \mathrm{a}, \mathrm{b}\end{array}$ & $1,790.72$ & $532.90-3,048.55$ & 14.00 \\
\hline $\begin{array}{l}\text { Total } \\
\text { excluding } \\
\text { prescription } \\
\text { medications }{ }^{a, c} \\
\end{array}$ & $6,990.56$ & $3,535.63-10,445.50$ & 34.77 \\
\hline \multicolumn{4}{|c|}{$\begin{array}{l}\text { aP<0.05 (significantly different). } \\
b^{b} \text { Others include glasses, ambulance, and equipment. } \\
{ }^{c} \text { Calculated as total health care expenditures minus prescription medication } \\
\text { expenditures. } \\
C I=\text { confidence interval; } M S=\text { multiple sclerosis. }\end{array}$} \\
\hline
\end{tabular}

\section{Strengths and Limitations}

The 2 major strengths of this study are the national representation and methodological rigor. This is the first study of its kind to use the TPM to analyze expenditures among the MS population. Moreover, this study provides an updated national estimate of marginal direct health care expenditures among individuals with MS.

From an economic point of view, the marginal cost estimate is more accurate than incremental or average cost estimate, which so far has not been reported in the literature. However, MEPS excludes high-cost populations (i.e., individuals in institutions and nursing homes) by limiting the survey to the civilian, noninstitutionalized population. Also, the majority of the study population had private insurance. Hence, the findings should be interpreted with caution and may not be representative of institutionalized patients. ${ }^{27}$

Health care costs among MS patients differ based on the type of MS, disease severity, and extent of disability. ${ }^{20}$ However, information related to MS type, severity, and other clinical parameters, such as the number of brain lesions and change in the expanded disability status scale scores, were not controlled because of the lack of such data in MEPS. ${ }^{26}$ Likewise, expenditures based on the type of DMA used could not be studied, since the focus was on overall health care expenditures. However, the prescription expenditures captured all prescriptions filled, including DMAs. 
MEPS data suffer from limitations such as under- or overreporting of medical information by household respondents, which could skew the study findings. Finally, this is a crosssectional, observational study design, which has inherent limitations such as selection bias and residual confounding.

\section{Conclusions}

MS is a chronic and disabling neurological disease with an extensive economic burden. Current study findings revealed that annual health care expenditures among individuals with MS are higher by approximately $\$ 20,000$ per person. A majority of the total health care expenditures were attributable to prescription medications. Even after the introduction of newer DMAs, the economic burden because of prescription medication has remained the same. High prescription expenditure burden has been reported as a barrier to providing optimal patient care in MS. Therefore, minimizing the coverage hurdles and copay burden for DMAs would improve the access to care and quality of care in MS.

\section{Authors}

JAGADESWARA RAO EARLA, PharmD, MBA; J. DOUGLAS THORNTON, PhD, PharmD, BCPS; and RAJENDER R. APARASU, PhD, FAPhA, Pharmaceutical Health Outcomes and Policy, College of Pharmacy, University of Houston, Texas. GEORGE J. HUTTON, MD, Baylor College of Medicine, Houston, Texas.

AUTHOR CORRESPONDENCE: Rajender R. Aparasu, PhD, FAPhA, Department of Pharmaceutical Health Outcomes and Policy, College of Pharmacy, University of Houston, Texas Medical Center, Health Bldg. 2, 4849 Calhoun Rd., Houston, TX 77204-5047. Tel.: 832.842.8374; E-mail: rraparasu@uh.edu.

\section{DISCLOSURES}

No funding was received for this study. Hutton reports grants from Adamas, Biogen, EMD Serono, Genzyme, Hoffman-LaRoche, MedImmune, Mallinckrodt, and Novartis and fees from Biogen, Celgene, Genzyme, Genentech, and Novartis, outside the submitted work. Aparasu reports grants from Novartis, Incyte, and Astellas, outside the submitted work. Earla and Thornton have nothing to disclose.

Part of the study findings was presented at the International Society for Pharmacoeconomics and Outcomes Research (ISPOR) 2019 National Conference; May 18-22, 2019; New Orleans, LA.

\section{REFERENCES}

1. Kamm CP, Uitdehaag BM, Polman CH. Multiple sclerosis: current knowledge and future outlook. Eur Neurol. 2014;72(3-4):132-41.

2. Lorefice L, Fenu G, Frau J, Coghe GC, Marrosu MG, Cocco E. Oral agents in multiple sclerosis. Antiinflamm Antiallergy Agents Med Chem. 2015;14(1):15-25.

3. Browne P, Chandraratna D, Angood C, et al. Atlas of multiple sclerosis 2013: a growing global problem with widespread inequity. Neurology. 2014;83(11):1022-24.
4. Schmidt C. Biology: a degenerative affliction. Nature. 2016;540(7631):S2-S3. 5. Dimitrov LG, Turner B. What's new in multiple sclerosis? Br J Gen Pract. 2014;64(629):612-13.

6. Vargas DL, Tyor WR. Update on disease-modifying therapies for multiple sclerosis. J Investig Med. 2017;65(5):883-91.

7. Thompson AJ, Baranzini SE, Geurts J, Hemmer B, Ciccarelli O. Multiple sclerosis. Lancet. 2018;391(10130):1622-36.

8. Prescott JD, Factor S, Pill M, Levi GW. Descriptive analysis of the direct medical costs of multiple sclerosis in 2004 using administrative claims in a large nationwide database. J Manag Care Pharm. 2007;13(1):44-52. Available at: https://www.jmcp.org/doi/10.18553/jmcp.2007.13.1.44.

9. Lorefice L, Fenu G, Pitzalis R, et al. Autoimmune comorbidities in multiple sclerosis: what is the influence on brain volumes? A case-control MRI study. J Neurol. 2018;265(5):1096-101.

10. Wallin MT, Culpepper WJ, Campbell JD, et al. The prevalence of MS in the United States: a population-based estimate using health claims data. Neurology. 2019;92(10):e1029-e40.

11. Ma VY, Chan L, Carruthers KJ. Incidence, prevalence, costs, and impact on disability of common conditions requiring rehabilitation in the United States: stroke, spinal cord injury, traumatic brain injury, multiple sclerosis, osteoarthritis, rheumatoid arthritis, limb loss, and back pain. Arch Phys Med Rehabil. 2014;95(5):986-95.e1.

12. Wingerchuk DM, Weinshenker BG. Disease modifying therapies for relapsing multiple sclerosis. BMJ. 2016;354:i3518.

13. Institute for Clinical and Economic Review. Disease-modifying therapies for relapsing-remitting and primary-progressive multiple sclerosis: effectiveness and value. Final evidence report. March 6, 2017. Available at: https://icer-review.org/wp-content/uploads/2016/08/CTAF_MS_Final_ Report_030617.pdf. Accessed April 27, 2020.

14. Edwards NC, Munsell M, Menzin J, Phillips AL. Comorbidity in U.S. patients with multiple sclerosis. Patient Relat Outcome Meas. 2018;9:97-102.

15. Capkun G, Dahlke F, Lahoz R, et al. Mortality and comorbidities in patients with multiple sclerosis compared with a population without multiple sclerosis: an observational study using the U.S. Department of Defense administrative claims database. Mult Scler Relat Disord. 2015;4(6):546-54

16. Owens GM. Economic burden of multiple sclerosis and the role of managed care organizations in multiple sclerosis management. Am J Manag Care. 2016;22(6 Suppl):s151-58.

17. Faguy K. Multiple sclerosis: an update. Radiol Technol. 2016;87(5):529-50. 18. Hartung DM, Bourdette DN, Ahmed SM, Whitham RH. The cost of multiple sclerosis drugs in the U.S. and the pharmaceutical industry: too big to fail? Neurology. 2015;84(21):2185-92.

19. Hartung DM. Economics and cost-effectiveness of multiple sclerosis therapies in the USA. Neurotherapeutics. 2017;14(4):1018-26.

20. National Multiple Sclerosis Society. Health policy fact sheet \#2. Available at: https://www.nationalmssociety.org/NationalMSSociety/media/ MSNationalFiles/Documents/Health-Policy-Fact-Sheet-2-Costs.pdf. Accessed April 27, 2020.

21. Direct costs. In: Kirch W, ed. Encyclopedia of Public Health. Dordrecht, Netherlands: Springer Netherlands; 2008:267.

22. Adelman G, Rane SG, Villa KF. The cost burden of multiple sclerosis in the United States: a systematic review of the literature. J Med Econ. 2013;16(5):639-47.

23. Carroll CA, Fairman KA, Lage MJ. Updated cost-of-care estimates for commercially insured patients with multiple sclerosis: retrospective observational analysis of medical and pharmacy claims data. BMC Health Serv Res. $2014 ; 14: 286$ 
24. Asche CV, Singer ME, Jhaveri M, Chung H, Miller A. All-cause health care utilization and costs associated with newly diagnosed multiple sclerosis in the United States. J Manag Care Pharm. 2010;16(9):703-12. Available at: https://www.jmcp.org/doi/10.18553/jmcp.2010.16.9.703.

25. Kobelt G, Berg J, Atherly D, Hadjimichael O. Costs and quality of life in multiple sclerosis: a cross-sectional study in the United States. Neurology. 2006;66(11):1696-702

26. Campbell JD, Ghushchyan V, Brett McQueen R, et al. Burden of multiple sclerosis on direct, indirect costs and quality of life: national U.S. estimates. Mult Scler Relat Disord. 2014;3(2):227-36.

27. Cohen JW, Cohen SB, Banthin JS. The medical expenditure panel survey: a national information resource to support healthcare cost research and inform policy and practice. Med Care. 2009;47(7 Suppl 1):S44-50.

28. National Center for Health Statistics. Ambulatory health care data: questionnaires, datasets, and related documentation. August 31, 2017. Available at: https://www.cdc.gov/nchs/ahcd/ahcd_questionnaires.htm. Accessed April 27, 2020.

29. Cohen J; Agency for Health Care Policy and Research. Design and methods of the Medical Expenditure Panel Survey Household Component. Methodology report 1. AHCPR Pub. No. 97-0026. July 1997. Available at: https://meps.ahrq.gov/data_files/publications/mrl/mrl.pdf. Accessed April 27, 2020.

30. Kachru N, Carnahan RM, Johnson ML, Aparasu RR. Potentially inappropriate anticholinergic medication use in older adults with dementia. J Am Pharm Assoc. 2015;55(6):603-12.

31. Cohen JW, Monheit AC, Beauregard KM, et al. The Medical Expenditure Panel Survey: a national health information resource. Inquiry. 1996;33(4):373-89.

32. Ozieh MN, Bishu KG, Dismuke CE, Egede LE. Trends in healthcare expenditure in United States adults with chronic kidney disease: 2002-2011. BMC Health Serv Res. 2017;17(1):368.

33. Agency for Healthcare Research and Quality. MEPS HC-110I: attachment 1. Clinical classification code to ICD-9-CM code crosswalk. 2018. Available at: https://meps.ahrq.gov/data_stats/download_data/pufs/h110i/hl10i_icd9codes.shtml. Accessed April 27, 2020.

34. Agency for Healthcare Research and Quality. MEPS HC-180: 2015 medical conditions. August 2017. Available at: https://meps.ahrq.gov/data_stats/ download_data/pufs/h180/hl80doc.pdf. Accessed April 27, 2020.
35. Agency for Healthcare Research and Quality. MEPS topics: health care costs/expenditures. April 3, 2019. Available at: https://meps.ahrq.gov/mepsweb/data_stats/MEPS_topics.jsp?topicid=5Z-1. Accessed April 27, 2020.

36. Wang G, Marrie RA, Salter AR, et al. Health insurance affects the use of disease-modifying therapy in multiple sclerosis. Neurology. 2016;87(4):365-74.

37. U.S. Bureau of Labor Statistics. CPI for all urban consumers. Available at: https://data.bls.gov/timeseries/CUUR0000SAM?output_view=data. Accessed April 27, 2020.

38. Park C, Fang J, Hawkins NA, Wang G. Comorbidity status and annual total medical expenditures in U.S. hypertensive adults. Am J Prev Med. 2017;53(6S2):S172-S81

39. Belotti F, Deb P, Manning WG, Norton EC. Twopm: two-part models Stata J. 2015;15(1):3-20

40. Glick HA, Doshi JA, Sonnad SS. Polsky D, ed. Economic Evaluation in Clinical Trials. Oxford: Oxford University Press; 2014.

41. Deb P, Norton EC. Modeling health care expenditures and use. Annu Rev Public Health. 2018;39:489-505.

42. O'Brien JA, Ward AJ, Patrick AR, Caro J. Cost of managing an episode of relapse in multiple sclerosis in the United States. BMC Health Serv Res. 2003;3(1):17.

43. Kim Y, Krause TM, Blum P, Freeman L. Disease modifying therapies continue to drive up health care cost among individuals with multiple sclerosis. Mult Scler Relat Disord. 2019;30:69-75.

44. Owens GM, Olvey EL, Skrepnek GH, Pill MW. Perspectives for managed care organizations on the burden of multiple sclerosis and the cost-benefits of disease-modifying therapies. J Manag Care Pharm. 2013;19(1 Suppl A):S41-53. Available at: https://www.jmcp.org/doi/10.18553/jmcp.2013.19. sl.S4l.

45. Johnson W. The rising cost of specialty drugs drove spending increases for people with multiple sclerosis 2019. Health Care Cost Institute. April 12, 2018. Available at: https://www.healthcostinstitute.org/research/publications/hcci-research/entry/the-rising-cost-of-specialty-drugs-drove-spendingincreases-for-people-with-multiple-sclerosis. Accessed April 27, 2020.

46. Minden SL, Frankel D, Hadden L, Hoaglin DC. Access to health care for people with multiple sclerosis. Mult Scler. 2007;13(4):547-58. 